\title{
SEMI-AUTOMATED ASSESSMENT OF MICROMECHANICAL PROPERTIES OF THE METAL FOAMS ON THE CELL-WALL LEVEL
}

\author{
Nela KrČmářováa ${ }^{a, b, *}$, Jan Šleichrt ${ }^{a}$, Tomáš DoKtor ${ }^{a}$, DAniel KYTÝ $\check{R}^{a, b}$, \\ ONDŘEJ JIROUŠEK ${ }^{a}$ \\ ${ }^{a}$ Czech Technical University in Prague, Faculty of Transportation Sciences, Konviktská 20, Prague 1, 15500 , \\ Czech republic \\ ${ }^{b}$ The Institute of Theoretical and Applied Mechanics AS CR, Prosecká 76, Prague 9, 190 00, Czech republic \\ * corresponding author: krcmarova@fd.cvut.cz
}

\begin{abstract}
Metal foams are innovative porous material used for wide range of application such as deformation energy or sound absorption, filter material, or microbiological incubation carrier. To predict mechanical properties of the metal foam is necessary to precisely describe elasto-plastic properties of the foam on cell-wall level. Indentation with low load is suitable tool for this purpose.

In this paper custom designed instrumented microindentation device was used for measurement of cell-wall characteristics of two different aluminium foams (ALPORAS and ALCORAS). To demonstrate the possibility of automated statistical estimation of measured characteristics the device had been enhanced by semi-automatic indent positioning and evaluation procedures based on user-defined grid. Vickers hardness was measured on two samples made from ALPORAS aluminium foam and one sample from ALCORAS aluminium foam. Average Vickers hardness of ALPORAS foam was 24.465 HV1.019 and average Vickers hardness of ALCORAS was 36.585 HV1.019.
\end{abstract}

KEYWORDS: metal foam, Vickers hardness, cell-wall, indentation under low loads.

\section{INTRODUCTION}

Metal foams are biomimetic porous materials with cellular inner structure that find wide range of applications from deformation energy absorption to noise attenuation, where their very high specific stiffness greatly improves overall effectiveness of constructions [1, 2]. Homogenization approach has been proposed as a method for prediction of their mechanical properties on both cell-wall level and at macroscale [36]. However for calculation of macroscopic (effective) mechanical properties by homogenization, mechanical characteristics at the lower level of the foam's hierarchical microstructure (i.e. cell-wall level) have to be assessed with high precision and reliability. Here microindentation is a suitable tool for assessment of required elasto-plastic material properties (for cellwall thicknesses from few hundreds of microns) with the possibility for extension to statistical estimation when automated indents' positioning and evaluation procedures are introduced.

\section{MATERIALS AND METHOdS}

\subsection{SPECIMEN DESCRIPTION AND PREPARATION}

Closed-cell aluminium foams with similar compound Al 97.0\%, Ca 1.5\%, Ti 1.5\% (measured using energydispersive X-ray spectroscopy) pore size $2-4 \mathrm{~mm}$ and wall thickness $100-200 \mu \mathrm{m}$ sales denominated as ALPORAS $^{\circledR}$ (Shinko Wire Co., Ltd., Japan) and

\begin{tabular}{lccc} 
& Sample 1 & Sample 2 & Sample 3 \\
\hline material & ALPORAS & ALCORAS & ALPORAS \\
\hline width & $48 \mathrm{~mm}$ & $41 \mathrm{~mm}$ & $44 \mathrm{~mm}$ \\
\hline height & $21 \mathrm{~mm}$ & $21 \mathrm{~mm}$ & $23 \mathrm{~mm}$ \\
\hline thickness & $10 \mathrm{~mm}$ & $11 \mathrm{~mm}$ & $13 \mathrm{~mm}$ \\
\hline
\end{tabular}

TABLE 1. Dimensions of the specimen

ALCORAS $^{\circledR}$ (AlCarbon, Germany) were subjected for the testing [7]. Inner structure of aluminium foam is depicted in Fig. 1. Figure was obtained using scanning electron microscopy MIRA II (TESCAN, Czech Republic). Region of interest was chosen according to avoid large pores and structural defect. The structural defects were mainly connected with ALCORAS sample. From the delivered slabs cuboids with minimal thickness of $12 \mathrm{~mm}$ (to ensure sample integrity) were sectioned using water cooled oscillating diamond saw (Isomet 1000, Buehler GmbH, Germany). Dimensions of each specimen are listed in Tab. 1 .

Low cutting speed $3 \mathrm{~mm} \cdot \mathrm{min}^{-1}$ minimised surface damage. Samples were embedded into mounting compound (VariKleer, Buehler GmbH, Germany). Grinding and polishing procedure employing silicon carbide grinding discs $(320,800,1200,4000$ grains per square inch) and diamond suspension $(1 \mu \mathrm{m})$ was performed to remove $1 \mathrm{~mm}$ surface layer which could be influenced by sectioning and to obtain plan-parallel faces 


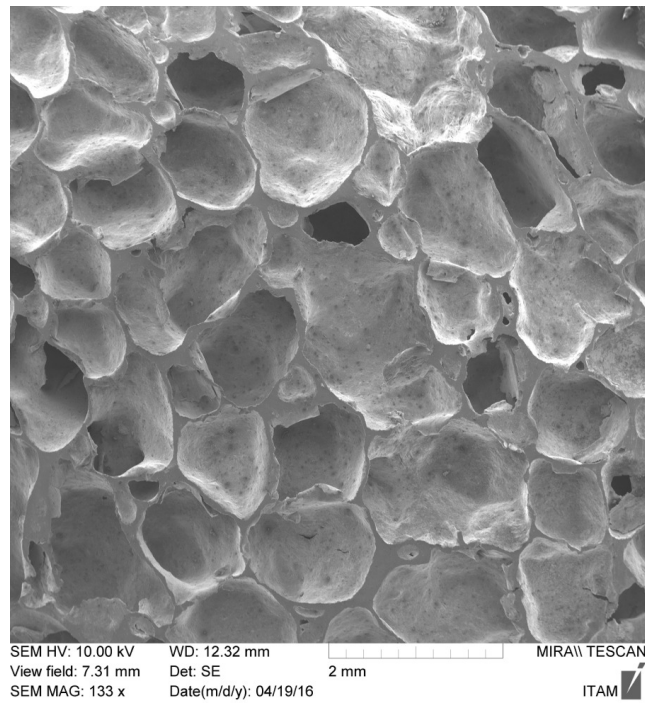

FigURE 1. Inner structure of aluminium foam obtained by scanning electron microscopy.

with minimal surface roughness necessary for proper indentation.

\subsection{INDENTATION TESTING}

\subsubsection{INDENTATION DEVICE DESCRIPTION}

Indentation testing was performed using custom designed indentation device developed and constructed on Department of mechanics and material FTS CTU. Indentation device is suitable for hardness measurement by low loads from $10 \mathrm{~N}$ up to $100 \mathrm{~N}$. Limitation of the device by applying lower loads are: i) inaccuracy of the load recorded by load-cell and ii) insufficient accuracy of the control of the indentation axis. Device consists of three independent motorised axes. Two of them are designed for precise positioning of the specimen with accuracy $10 \mu \mathrm{m}$. Third axis is indentation axis equipped by load-cell with positioning accuracy $1.5 \mu \mathrm{m}$. Device is controlled by load or displacement using GNU/Linux software system LinuxCNC with custom made graphical user interface. Device is equipped with CCD camera (Manta G-504B, AVT, Germany) with a resolution of $2452 \times 2056 \mathrm{px}$ attached to a light microscope (Navitar Imaging, Inc., USA) that provided a magnification of up to $24 \times$. The acquisition of the projections was controlled by in-house-built OpenCV based plug-in integrated to control software 8. Indentation device is depicted on Fig. 2

This camera is used for the indent place estimation as well as to make a photo of the indent that is than used for hardness measurement. Due to high resolution CCD camera, calibrated indentation tip alignment and precise positioning of the specimen, indentation of the selected location of the specimen's surface is allowed with high accuracy. For verification of the device accuracy of hardness measurement indentation in calibration hardness plate was performed. Device overall error estimated by calibration mea-

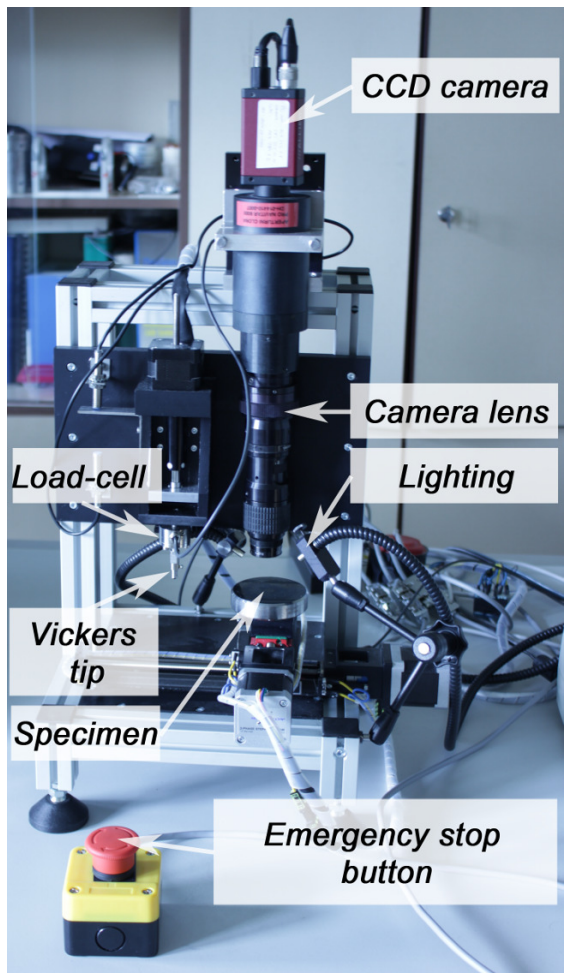

Figure 2. Experimental setup.

surement was $1.3 \%$. Maximal measurement error for indentation devices is according to standard set to $3 \%$. It can be advantageously used for measuring hardness of metal foams because indentation is possible only in places with a sufficient width and depth of the specimen, which means joints of the walls.

\subsubsection{EXPERIMENT PROCEDURE DESCRIPTION}

Suitable places for indentation on the sample surface were identified using CCD camera and subsequently indentation was automatically performed at these selected locations. After the indentation image data of each indent were captured. The detail of an indent is depicted on Fig. 3 Indentation load was set to $10 \mathrm{~N}$ and this value was reached in $10 \mathrm{~s}$. First indent was used as a testing indent to find indentation speed to respect the condition of reaching maximal force value in $10 \mathrm{~s}$. This indent was removed from data set and hardness value of this indent was not evaluated. All other indents were displacement controlled with given speed identified by the testing indentation. Course of the indentation was therefore: i) $10 \mathrm{~s}$ loading up to $10 \mathrm{~N}$, ii) $10 \mathrm{~s}$ holding on the indentation load and iii) unloading with the same speed as the loading phase.

On each specimen was created a series of about 50 indents on the interconnections of the walls. The foam microarchitecture with poresize $2-4 \mathrm{~mm}$ ensure avoiding that the plastic zones of the indents don't affect each other. Because of size of interconnection and limited minimal indentation force normative $2.5 \times$ diameter distance from sample edge can't be meet during experimental procedure. Size of thus generated imprints of the indenter was about $270 \mu \mathrm{m}$ and their 


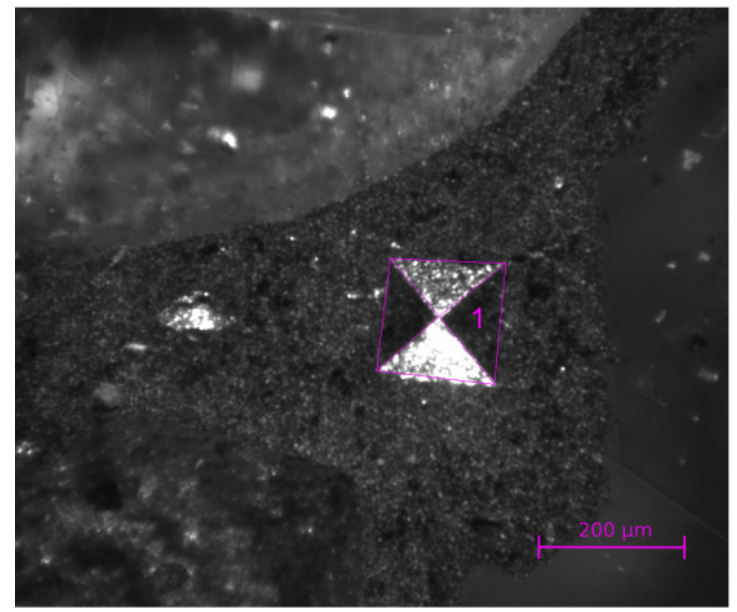

FiguRE 3. Right: Marked area of the imprint obtained by semi-automatic evaluation method.

depth was about $39 \mu \mathrm{m}$.

\subsubsection{EVAluation OF THE EXPERIMENTAL DATA}

Positioning accuracy of the indentation axis does not allow automated evaluation of the hardness from the full position-load curve using Oliver-Pharr method [9]. Therefore hardness was assessed using traditional method by measuring the imprint dimensions and evaluated as Vickers hardness:

$$
H V=\frac{F}{A} \approx \frac{0.1819 F}{d^{2}},
$$

where $F$ is indentation load in N, $A$ is resulting indentation area of the imprint of the indenter in $\mathrm{mm}^{2}$ and $d$ is average length of the diagonal of the imprint of the indenter in $\mathrm{mm}$. As indentation load is taken the maximal force value registered by the loadcell. Length of the diagonals in pixels was measured from the image of each imprint of the indenter using semi-automatic method in Matlab software. Image of the calibration pattern was used for conversion of the diagonal length in pixels to millimetres. Highlighted imprint of the indenter is depicted on Fig. 3

\section{Results}

Elasto-plastic material properties of two types of aluminium foam was measured by Vickers hardness. Indentation was performed on cell walls and their connections to ensure sufficient place for indentation. In order to get precise information about micromechanical properties of the foam about 50 indents were carried out at each of the three specimens. Due to foam nature of specimens the under surface area can be formed by cavity which is not visible on the surface and thus some indents were deformed and these Vickers hardness values are omitted from the data set. Those indents are usually easily recognised by highly deformed shape of indents. Success of the indention was about $60 \%$. Hardness values calculated using equation 1 are listed in Tab. 2
Sample 1 Sample 2 Sample 3

\begin{tabular}{|c|c|c|c|}
\hline material & ALPORAS & ALCORAS & ALPORAS \\
\hline Indent 1 & 24.630 & 41.507 & 18.149 \\
\hline Indent 2 & 33.008 & 35.490 & 29.839 \\
\hline Indent 3 & 25.204 & 36.360 & 24.817 \\
\hline Indent 4 & 23.027 & 32.990 & 23.672 \\
\hline Indent 5 & 21.665 & 31.514 & 20.633 \\
\hline Indent 6 & 22.818 & 34.447 & 22.967 \\
\hline Indent 7 & 22.211 & 30.213 & 23.779 \\
\hline Indent 8 & 24.547 & 30.254 & 16.826 \\
\hline Indent 9 & 35.845 & 49.110 & 15.233 \\
\hline Indent 10 & 33.856 & 47.130 & 13.301 \\
\hline Indent 11 & 27.067 & 45.138 & 15.093 \\
\hline Indent 12 & 33.404 & 28.928 & 24.319 \\
\hline Indent 13 & 25.699 & 38.507 & 33.361 \\
\hline Indent 14 & 21.559 & 24.547 & 13.418 \\
\hline Indent 15 & 25.510 & 41.085 & 25.044 \\
\hline Indent 16 & 27.996 & 37.927 & 16.167 \\
\hline Indent 17 & 32.651 & 42.484 & 18.410 \\
\hline Indent 18 & 29.958 & 30.323 & 19.584 \\
\hline Indent 19 & 31.472 & 32.506 & 24.322 \\
\hline Indent 20 & 21.663 & 43.721 & 21.050 \\
\hline Indent 21 & 23.802 & 34.975 & 24.192 \\
\hline Indent 22 & 30.054 & 32.557 & 31.487 \\
\hline Indent 23 & 34.450 & 28.754 & 15.765 \\
\hline Indent 24 & 29.011 & 45.065 & 26.474 \\
\hline Indent 25 & 21.114 & 33.645 & 15.346 \\
\hline Indent 26 & & 40.693 & 24.999 \\
\hline Indent 27 & & 39.462 & 26.053 \\
\hline Indent 28 & & 35.017 & \\
\hline Indent 29 & & 39.386 & \\
\hline Indent 30 & & 33.801 & \\
\hline Avarage & 21.641 & 36.585 & 27.289 \\
\hline
\end{tabular}

TABLE 2. Values of measured Vickers hardness by indentation load $10 \mathrm{~N}$

As can be seen from the hardness values summarised in Tab. 2 Vickers hardness of ALPORAS aluminium foam is about $30 \%$ lower than Vickers hardness of ALCORAS aluminium foam.

\subsection{Comparative measurement}

To ensure reliability of the indentation process with non-standarded indents size digital microscope VHX- 


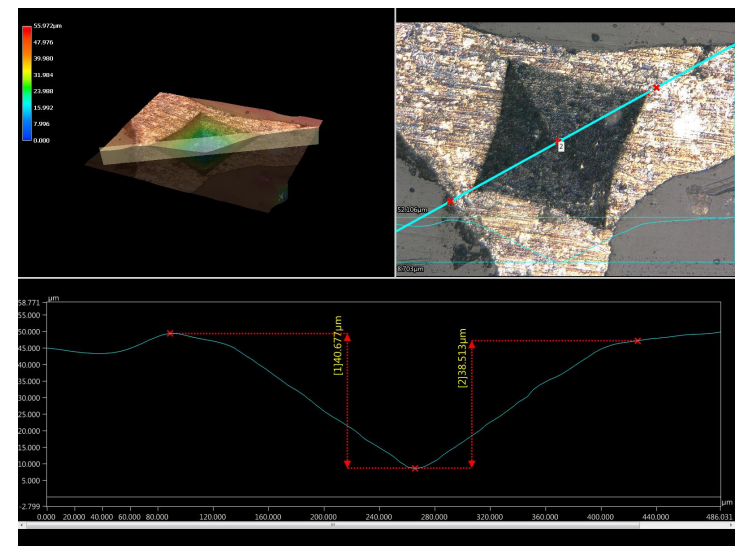

FigURE 4. Indent surface inspection and indent profile reconstruction equipped by digital microscope.

5000 (Keyence, Japan) was employed for indented surface inspection and indent profile reconstruction (see Fig. 4). Indentation depth $\approx 40 \mu \mathrm{m}$ was obtained from indent profile using Keyence proprietary software. This value corresponds to results of the analysis presented in 2.2.2 The profile is not significantly effected by surrounding embedding resin.

\section{Conclusions}

Vickers hardness measurement was performed on three samples of aluminium foam on cell-wall level. One sample was aluminium foam ALCORAS and two samples were made of aluminium foam ALPORAS. About 50 indents were created on each sample on the cellwalls or their interconnections with indentation load 10 N. Success of the indentation was about $60 \%$ other indents were deformed due to wrong position on the sample surface what was not possible to avoid prior the indentation. Indentation was carried out using custom designed indentation device equipped with load-cell and CCD camera. Camera was used for identification of appropriate place for indentation and for acquisition of image data of each imprint. Vickers hardness was evaluated from image data using semi-automatic procedure in software Matlab.

Average Vickers hardness of the sample 1 (ALPORAS foam) was $21.641 \pm 5.496 \mathrm{HV} 1.019$, where HV is denotation for Vickers hardness and value 1.019 indicates indentation load in kgf. Average Vickers hardness for sample 3, which was also made from ALPORAS, was 27.289 $\pm 4.731 \mathrm{HV} 1.019$. Average Vickers hardness of the third sample, which was made from ALCORAS foam, was $36.585 \pm 6.061 \mathrm{HV} 1.019$. Vickers hardness of ALCORAS aluminium foam is about $30 \%$ higher than Vickers hardness of ALPORAS aluminium foam. Information about elasto-plastic properties of the aluminium foams ALPORAS and ALCORAS on cell-wall level can be used for calculation of macroscopic mechanical properties by homogenization.

\section{ACKNOWLEDGEMENTS}

The research was supported by the Czech Science Foundation (research project No. 15-15480S), by Czech technical university in Prague (research project No. SGS15/225/OHK2/3T/16) and by institutional support RVO: 68378297 . Keyence is kindly acknowledged for providing of digital microscope VHX-5000.

\section{REFERENCES}

[1] T. Miyoshi, M. Itoh, S. Akiyama, A. Kitahara. Alporas aluminum foam: Production process, properties, and applications. Advanced Engineering Materials 2(4):179-183, 2000. DOI:10.1002/(SICI)15272648(200004)2:4<179::AID-ADEM179>3.0.CO;2-G.

[2] M. Idris, T. Vodenitcharova, M. Hoffman. Mechanical behaviour and energy absorption of closed-cell aluminium foam panels in uniaxial compression. Materials Science and Engineering: A 517(1-2):37 - 45, 2009. DOI:http://dx.doi.org/10.1016/j.msea.2009.03.067

[3] P. Koudelka, T. Doktor, J. Valach, et al. Effective elastic moduli of closed-cell aluminium foams homogenization method. 11th IMEKO TC15 Youth Symposium on Experimental Solid Mechanics 2012 pp. 244-250, 2012.

[4] S. Li, D. Qian, M. L. and. Multiscale mechanics and mechanics of biological materials.

[5] V. Králík, J. Němeček. Micromechanical properties of porous material based on metal foam. Chemicke Listy 105(17):s672-s675, 2011.

[6] M. Geißendörfer, A. Liebscher, C. Proppe, et al. Stochastic multiscale modeling of metal foams. Probabilistic Engineering Mechanics 37:132-137, 2014. DOI:10.1016/j.probengmech.2014.06.006

[7] T. Fíla, D. Kytýřr, P. Koudelka, et al. Micro-mechanical testing of metal foam cell walls using miniature threepoint bending. Key Engineering Materials 586:120-124, 2014. DOI:10.4028/www.scientific.net/KEM.586.120

[8] G. Bradski. The opencv library. Dr Dobb's: The World of Software Development 2000.

Http://www.drdobbs.com/open-source/the-opencvlibrary/184404319.

[9] W. Oliver, G. Pharr. An improved technique for determining hardness and elastic modulus using load and displacement sensing indentation experiments. Journal of Materials Research 7(06):1564-1583, 1992. 